JSCN T

Journal of Sustainable Construction Materials and Technologies
Journal of Sustainable Construction Materials and Technologies

https://jscmt.org/

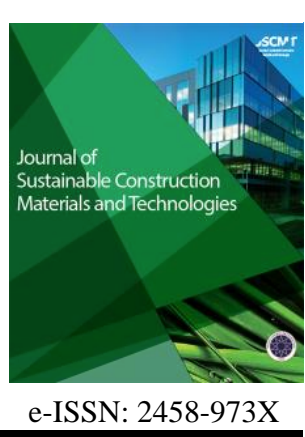

Review Article

\title{
Sustainable Practices in Bridge Construction
}

\author{
Balaji Venkateswaran ${ }^{\mathrm{a}, *, \text { C }}$ \\ ${ }^{a}$ Department of Civil Engineering, Anna University, Chennai, Tamil Nadu, India
}

\begin{abstract}
This paper throws light on the importance of sustainability in bridge construction projects and explains the methods to achieve sustainability in construction of bridges. The essential methods to achieve sustainability on various phases of a bridge project i.e., right from planning to maintenance of a bridge project during its service is also explained. The necessity of enacting laws to make sustainability as mandatory is outlined as conclusion.
\end{abstract}

Keywords: Bridge; Concrete; Construction; Sustainability; Life Cycle

\section{Introduction}

Sustainability is a practice in a way that the natural resources are used effectively in mining, product conversion, product production and maintenance, as a result of which, the natural resources are carried over to the future generations, without exhausting them rapidly.

Mankind has been constructing buildings, roads, bridges, railway lines, factories etc., enormously since the advent of industrial revolution. The pace of construction has always been increasing steadily around the globe, especially in fast developing countries such as India, China, Brazil, South Africa etc. Construction of structures consumes natural resources to a large extent.

The sustainability in construction could be achieved by the use of natural resources through minimising embodied energy and operational energy. Bridge construction has a substantial share in construction of infrastructure systems all over the world. Bridges are proposed over river crossing as river bridges, over and below the roads and railway lines in the form of fly overs and under bridges. Bridges are essential part of any transportation system. Bridges with spans of up to $30 \mathrm{~m}$ constitute the vast majority of road infrastructure bridges in service across the world [2]. Higher is the construction area of a bridge project, higher is the consumption of natural resources. Hence astute planning is required for the construction of a bridge project in order to achieve sustainability.

This paper was recommended for publication in revised form by Editor Mukhallad Al-mashhadani *Corresponding author/E-mail address: bakrkaku@gmail.com (B. Venkateswaran) https://doi.org/10.29187/jscmt.2021.56 


\section{Sustainability Thinking in Bridge Construction}

Sustainability in bridge construction could be achieved through planning, design, construction and maintenance of a bridge [5]. Sustainability in a bridge project could be viewed from achieving minimum embodied and operational energy during its construction and maintenance [2].

\subsection{Embodied Energy}

Embodied energy in a bridge project results from the use of materials for the construction of a bridge, i.e., energy consumed by the materials in mining, stacking, sorting, conversion in to other products, transportation of the converted product, their storage or laying the finished products in their intended place.

\subsection{Operational Energy}

Operational energy is the energy consumed in operation and maintenance of a bridge structure, during its entire life span. In order to achieve sustainability in construction of bridges, their embodied energy and operational energy should be minimum.

\subsection{Sustainability in Planning a Bridge Project}

Planning for a bridge project involves selecting a suitable location for the bridge in terms of minimum length of the proposed bridge, selecting an economic span for the bridge and selection of suitable superstructure forms such as girder bridge, arch bridge, suspension bridge, cable stayed bridge etc. The form of sub structure to be selected for a bridge project depends upon its height and the span proposed. The foundation for a bridge project depends upon the soil profile at the project location based on which the foundation shall be of pile, raft and open spread footing.

Selection of particular location for a bridge project, its superstructure, sub structure and foundation contribute a lot in achieving sustainability. A perspective that longer the bridge, higher is the material consumption for construction and the maintenance shall also be considered. The selection of site for a bridge construction shall also be made in such a way that neither its approach nor its span is located on the wet irrigation fields, forest area, lakes, tanks, reservoirs, zoological conservatories etc., in such as way that micro climate of the region, habitats of the region are not affected and water retention area of the water bodies are not shrunk in any way. The bridge should also be planned in such a way that livelihood of people living in the area is not affected in any way. Planning should also be in such a way that the natural formations such as hills, mountain ranges are not affected.

New bridge in lieu of the existing bridge may be planned if it is absolutely essential to reconstruct the bridge otherwise the existing bridge may be strengthened to achieve extension of its service life.

\subsection{Sustainability in Design of Bridges}

The design components of a bridge structure must be meticulously done in such a way the structure integrates well in to the atmosphere. The structure should not be a loner in the surroundings. The bridge span, material for construction of the bridge, location of piers and abutments, construction of retaining walls to retain the approaches or river bunds, river bed protective works are all designed in such a way that they consume minimum natural resources and deployment of machineries for their construction.

Design of bridges should be in such a way that they need less repair and restoration effort during their entire service life. Possibility of use of locally available materials and the use of recycled materials should also be explored in the design stage. The use of alternate and appropriate technologies should also be explored.

\subsection{Analysis for Life Cycle Analysis of a Bridge Structure}

Life Cycle Analysis (LCA) [1,2] is a method to evaluate all the aspects connected with bridge construction and its associated environmental impacts during its entire service life including its material procurement, their transportation, use, and their final disposal in such a way that the net embodied energy, operational energy and the emission of carbon dioxide $\left(\mathrm{CO}_{2}\right)$ is minimum. As in Figure 1. [4] the LCA also aims to achieve balance in economics i.e., the cost incurred in construction and 
maintenance of a bridge structure, maintaining the environment of the locality (The minimum change in micro and macro climate of the area and the minimum disturbance to habitat of the region) and the social impacts due to construction. (The impact on the livelihood of the locality should be minimum, rehabilitation and resettlement should also be kept minimum).

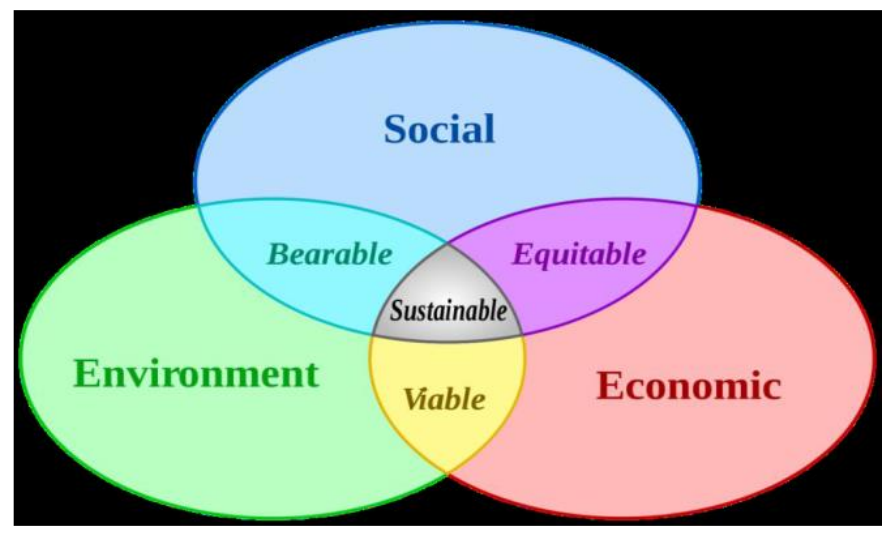

Figure 1. Sustainable Parameters

Thus, a sustainable bridge project, as shown in Figure 1. [4] shall be economically viable, environmentally justifiable or bearable and must create an equitable social environment.

In any bridge project, common materials for use in their construction are concrete, steel and composites of steel and concrete. Table 1. Shows the embodied energy and $\mathrm{CO}_{2}$ emissions on different forms of bridge structures using different materials for their construction [2]. It can be inferred from the above table that considering various bridge forms, bridge constructed using concrete consumes less energy and emit minimum $\mathrm{CO}_{2}$ emission.

Table 1. Bridge forms and embodied energy consumption

\begin{tabular}{|c|c|c|c|c|c|c|c|}
\hline \multirow[b]{2}{*}{ Energy } & \multirow{2}{*}{$\begin{array}{l}\text { Structural } \\
\text { From } \\
\text { Type } \\
\end{array}$} & \multicolumn{3}{|c|}{$\begin{array}{c}\text { Embodied Energy during } \\
\text { construction }\left(\mathrm{GJ} / \mathrm{m}^{2)}\right.\end{array}$} & \multicolumn{3}{|c|}{$\begin{array}{l}\mathrm{CO}_{2} \text { Emissions during } \\
\text { construction }\left(\mathrm{Kg} / \mathrm{m}^{2}\right)\end{array}$} \\
\hline & & steel & Concrete & Composite & steel & Concrete & Composite \\
\hline & Viaduct & 17.6 & $15.7 / 16.6$ & 22.1 & 1464 & $1445 / 1446$ & 1453 \\
\hline \multirow[t]{4}{*}{ Minimum } & Girder & 30.9 & 23.6 & 29.1 & 2513 & 2132 & 2440 \\
\hline & Arch & 49.5 & 34.3 & 48.8 & 3952 & 3536 & 4036 \\
\hline & $\begin{array}{l}\text { Cable- } \\
\text { stay }\end{array}$ & 40.3 & $21.1 / 22.1$ & 37.7 & 3406 & 3242 & 3372 \\
\hline & Viaduct & 23.3 & $21.1 / 22.1$ & 22.1 & 1719 & $1710 / 1863$ & 1702 \\
\hline \multirow[t]{4}{*}{ Average } & Girder & 39.3 & 30.6 & 37 & 2810 & 2457 & 2750 \\
\hline & Arch & 61.9 & 49.1 & 60.8 & 4326 & 4005 & 4459 \\
\hline & $\begin{array}{l}\text { Cable- } \\
\text { stay }\end{array}$ & 50.6 & 43.9 & 47.7 & 3822 & 3726 & 3830 \\
\hline & Viaduct & 30.8 & $28.1 / 28.6$ & 29.2 & 1891 & $1912 / 2066$ & 1893 \\
\hline \multirow[t]{3}{*}{ Maximum } & Girder & 49.3 & 39.1 & 46.6 & 3045 & 2718 & 2998 \\
\hline & Arch & 75.6 & 60.9 & 74.4 & 4637 & 4410 & 4820 \\
\hline & $\begin{array}{l}\text { Cable- } \\
\text { stay }\end{array}$ & 62.6 & 54.8 & 69.3 & 4174 & 4140 & 4244 \\
\hline
\end{tabular}

\subsection{Sustainability in Construction of Concrete Bridges}

Sustainability in construction could be achieved in many ways. The chief among them are.

- Procurement of materials 
- Storing/Stacking of materials

- Testing of materials

- Use of materials for construction

- Construction techniques

- Project management

- Maintenance of the structural components

\subsubsection{Procurement of Materials}

The essential procurements for a bridge structure consist of:

- Cement

- Steel

- Coarse aggregates and fine aggregates

- Earth for formation of approaches

Cement of required grade should be produced in bulk rather than in loose quantities. This reduces the cost of fuel used for transportation and in turn reduces operation energy. The procured cement should be stored in such way that the cement should be used till the end of the construction without any loss in the property of cement.

Steel of required quality and quantity should be procured well in advance before the commencement of RCC construction. They should be cut in such a way that wastages are minimum.

Coarse and fine aggregates should be sourced nearer to the site and the use of locally available materials should be encouraged. Earth of required quality should be sourced nearer to the site rather than conveyed from a distance.

\subsubsection{Stacking}

Stacking of construction materials should be done nearer to the site. In the case of concrete, the raw materials should be stored in such a way that batching of concrete is done quickly, without any need for longer conveyance for mixing and placing of concrete.

\subsubsection{Testing of materials}

Testing and certification of materials should be carried at the source itself rather than at the site. This obviates the necessity for return transportation, if there is any need for rejection of materials.

\subsubsection{Construction Techniques}

Construction of the bridge components should be planned in such a way that each of them is carried out in minimum possible time by employing suitable construction techniques. Time delay and cost overrun are indirectly related to sustainable construction. The form work and scaffolding materials should be of such a quality so that the finished concrete is within the tolerance limits and the form work materials can be reused to the maximum extent as possible, without any loss in their integrity and the finished concrete is not out of dimension.

\subsubsection{Project Management}

Project management contributes to the sustainable goals by means of effective utilisation of resources and manpower. Scientific implementation of a bridge project by means of employing construction management principles shall be explored. The use of Project Evaluation and Review Technique (PERT), Critical Path Method (CPM)) and the project management software tools such as PRIMAVERA for large projects, shall also be considered. 
The concept of Building Information modelling (BIM) shall also be considered for the bridges as various stages of a bridge project are integrated in to a single model i.e., right from planning, design, and estimation to the execution. This proves to be cost effective and contributes to sustainability in a huge way.

\subsubsection{Maintenance of the Structural Components}

The maintenance of a bridge structure contributes a lot to the sustainability. Maintenance includes adhering to the quality control norms during construction, particularly in areas with severe exposure conditions. In order to meet norms for severe exposure conditions, larger cover for concrete components is prescribed, treatments of steel using epoxy coatings, use of Sulphate resistant cement for foundation are also prescribed.

Apart from the above, routine inspection and testing are also needed to ensure that the bridge components complete their service life satisfactorily. Undertaking immediate repair of any faulty components also ensures the structural integrity of the bridge structure. The maintenance of the bridge components in a routine manner also makes the structure to live beyond their service life. Extending the life of a bridge structure also make them sustainable.

\section{Conclusion}

The bridges are vital infrastructures of any economy. Wherever the economy is growing, the bridge infrastructure also increases. As a result, sustainability has become an important factor to look in to so that the bridge structures are not only sustainable but are also cost effective. This results in substantial saving in economy, particularly in developing countries. Thus, sustainability should be an integral part of an estimate for any bridge project. Construction rules globally should be enacted so that the sustainability is given due consideration for any bridge project.

\section{Acknowledgement}

The author wishes to acknowledge all researchers, scientist, planners, builders, government agencies, interest groups who work to achieve sustainability a way of practice and thus to save our planet from imminent catastrophe.

\section{Conflict of interest}

The author declared no potential conflicts of interest with respect to the research, authorship, and/or publication of this article.

\section{Ethics}

There are no ethical issues with the publication of this manuscript.

\section{References}

[1] Ahlborn,T., (2020, January 10). Sustainability For the Concrete Bridge Engineering Community, ASPIRE Magazine, Precast concrete Institute, Winter Issue. http://aspirebridge.com/magazine/2008Winter/ASPIRE_win08.pdf

[2] Buffenbarger, J., (2020, January 10). Sustainable Bridges and Infrastructure (Part II), U.S. Department of Federal Highway Administration, Issue 77, http://www.concretebridgeviews.com

[3] Long, A. E., Venables R. K., Ferguson J. D., (2020, January 10) . Sustainable bridge construction through innovative advances, Queen's University, Belfast, U.K., Accessed on line 2020, http://www.irbnet.de/daten/iconda/CIB11831.pdf

[4] Myint, L. (2019). LRFD Bridge design manual ,Sustainable bridge design, IOWA Department of Transportation Des Moines, Iowa, USA.

[5] Whittmore, D., (2020, January 10). Sustainable structures for the bridge engineer, Structure Magazine, Accessed on line $2020 \mathrm{http}: / / \mathrm{www}$. concretebridgeviews.com 